\title{
Entre bois e cabras: uma visão histórica sobre mentalidades e valores nos sertões
}

\section{Between cattle and goats: a historical view about mentalities and values in the Brazilian Northeastern backlands}

Oswaldo Gonçalves Júnior

\section{Introdução}

Pesquisas recentes realizadas nos estados do Rio Grande do Norte, Paraíba e Ceará - especialmente em suas porções semi-áridas, tendo como preocupação central o tema da construção social de mercados da caprinovinocultura constataram a existência subjacente de uma problemática intrigante. Embora tenham se disseminado pelo território nordestino de forma impressionante desde

Oswaldo Gonçalves Junior é mestre em Educação pela Faculdade de Educação da Universidade de São Paulo (FEUSP) e doutor em Administração Pública e Governo pela Escola de Administração de Empresas da Fundação Getúlio Vargas de São Paulo (EAESP-FGV), São Paulo, Brasil (osgoju@yahoo.com.br). Artigo recebido em 17 de novembro de 2010 e aprovado para publicação em 29 de março de 2011. 


\section{Oswaldo Gonçalves Júnior}

sua introdução pelos colonizadores portugueses no século XVI, caprinos e ovinos vêm sendo vistos, ao longo do tempo, de maneira inferiorizada em relação aos bovinos, cuja criação conferiria prestígio e status social.

No cotidiano, ao lado de outros animais também considerados "menos importantes", caprinos e ovinos são genericamente denominados de "miunça", que significa "criação de pouco valor". Pragmaticamente, no entanto, essa hierarquização é contraditória. Afinal, a criação de caprinos e ovinos é mais adaptada às duras condições do semi-árido do que a de bovinos, cujas perdas recorrentes de animais, em decorrência das drásticas secas, geraram e geram um ambiente de instabilidade, contribuindo em muitos casos para perpetuar a pobreza dos criadores da região.

Porém, mesmo diante dessas evidências concretas, sentidas na pele por boa parte da população do semi-árido, observou-se, e observa-se, uma forte resistência em relação ao potencial econômico da caprinovinocultura naquela região. Ainda hoje, essa modalidade de pecuária é desenvolvida, grosso modo, sob bases domésticas e sem a incorporação de aprimoramentos técnicos, o que a torna um segmento pouco produtivo em termos econômicos, incapaz de alterar de forma significativa a qualidade de vida de boa parte dos produtores. Em termos comerciais, chama a atenção o fato de que a desorganização da prática da caprinovinocultura vem condicionando uma demanda reprimida, dada a baixa oferta de produtos, sobretudo aqueles de qualidade, condizente com o abastecimento de mercados mais estruturados. A desarticulação da atividade é tamanha que sequer dá conta da significativa demanda do mercado nordestino, que, assim, é atendida pela importação de carne. Recentemente, estimou-se o "déficit de carne de caprinos e ovinos [na região] em torno de 13 mil toneladas/ano" (Nobre, 2007: 26). O fato é que a insistência nesse comportamento contrário à criação de caprinos e ovinos, como apontam diversos estudos, vem desperdiçando um enorme potencial.

Ainda que o presente trabalho derive de uma pesquisa cujo foco de preocupação aborda uma problemática atual - a construção social de mercados da caprinovinocultura -, entendeu-se, no seu transcorrer, como necessário e fundamental lançar um olhar sobre o passado, recorrendo-se para isso à produção de autores que contribuíram decisivamente para as ciências sociais no Brasil. Em outras palavras, o que Capistrano de Abreu, Gustavo Barroso, Caio Prado Junior, Euclides da Cunha, Sergio Buarque de Holanda, Gilberto Freyre, Manuel Correia de Andrade, entre outros, disseram, quando voltaram suas atenções para o deslocamento colonizador e para a pecuária dos sertões, que poderia ajudar na compreensão da problemática apontada?

Pretende-se que este artigo contribua, fundamentalmente, para tornar mais claras as raízes do aparato cognitivo de parte da população nordestina que 
atrela, ainda nos dias de hoje, a criação de bovinos a prestígio e status social, e qualifica caprinos e ovinos como "miunça", o que tem gerado desdobramentos negativos para o desenvolvimento socioeconômico da região.

Partindo do pressuposto de que a cultura é importante para a conformação do "mundo econômico", procurou-se compreender como o processo histórico de organização econômica e social desse espaço influencia o presente, sobretudo no que tange às resistências muitas vezes manifestas por parte de agricultores e que se contrapõem à aceitação da caprinovinocultura como atividade com potencial econômico. Nesse sentido, em última análise, pretende-se que as evidências a serem apresentadas neste artigo também venham a contribuir para avançar na compreensão de como motivações tidas como "não econômicas" incidem sobre a conformação da economia, por vezes tomada de forma autônoma e pouco afetada pelas relações sociais.

\section{Em direção aos sertões}

Na fase inicial da colonização do território brasileiro - com exceção de São Paulo, centro de expansão dos bandeirantes -, todos os núcleos da ocupação colonizadora ficavam no litoral. Tal constatação levou Frei Vicente de Salvador, em sua História do Brasil, obra de 1627, a comparar os portugueses a caranguejos, analogia inúmeras vezes repetida para ressaltar o desinteresse em se adentrar o continente e repovoá-lo, situação que não permaneceria assim por muito tempo (Holanda, 1960: 218).

No Nordeste, isso começou a se transformar com a introdução do gado. Com efeito, as consequências do movimento de deslocamento da costa em direção aos sertões, onde os portugueses empreendendo atividades pastoris, foram decisivas para o perfil da colonização. $O$ novo rumo seguido pelos colonizadores levou autores como Gustavo Barroso a afirmar que nenhuma palavra é mais ligada à história do Brasil, em especial a história do Nordeste, do que a palavra sertão. Ela surgiu, já no início da colonização, "rotulando o interior das terras", ainda que isso não tenha sido uma particularidade das terras daqui, pois os portugueses já tinham feito uso do termo em suas colônias de outros continentes e na própria metrópole, utilizando-o para designar qualquer "locus mediterraneus" (Barroso, 2004: 9).

No nosso caso, de acordo com Manuel Correia de Andrade, considerando-se a classificação das regiões geográficas do Nordeste, o Sertão seria uma das três grandes divisões que, juntamente com a Mata e o Agreste, caracterizam grosso modo aquela região do país. Ainda segundo Andrade, se pelo menos um elemento sempre se sobressai na caracterização das paisagens, no Nordeste este 


\section{Oswaldo Gonçalves Júnior}

elemento é o clima. Assim, foi o clima quente e úmido, com duas estações bem definidas, uma chuvosa e outra seca, que, desde os tempos coloniais, definiu a Zona da Mata, área ocupada primordialmente pela cultura canavieira, pelas grandes fazendas e pelos engenhos. Já o Sertão - caracterizado também pelo clima quente, porém seco, e sujeito a rigorosas secas periódicas - era a área por excelência da pecuária extensiva, que predominou naquele espaço ao longo dos séculos. Entre as duas regiões situa-se o Agreste, zona de transição, com trechos secos e outros úmidos, contemplando, de forma intercalada, os dois sistemas mencionados anteriormente, e acolhendo atividades tanto agrícolas quanto pastoris, conforme dinâmicas específicas no decorrer do processo histórico (Andrade, 1998).

Considerando-se a dinâmica de deslocamento e (re)ocupação do território, a presença do gado contribuiu decisivamente para alterar a fisionomia da paisagem em seus traços essenciais (Freyre, 2004). Assim, no início do século XVIII a analogia aos caranguejos já perdera a razão de ser. Antonil e Rocha Pitta não escondem sua admiração ao destacarem o alargamento do "território rasgado pelos cascos de boi" (Alencastro, 2000: 340). Como lembra Alencastro, Antonil, ao descrever a dimensão das boiadas, sabendo que seus leitores estavam habituados aos parcos rebanhos europeus, "conclui prudentemente: temo que não seja crível” (Alencastro, 2000: 340). Com o passar do tempo, o contínuo processo de alargamento do território pelos deslocamentos que levavam à ocupação do Sertão, acompanhado do número igualmente crescente de animais das criações, continuou surpreendendo seus observadores, até alcançar mais tarde a dimensão de "civilização do couro", na definição de Capistrano de Abreu.

\section{O avanço da pecuária e das transformações sociais}

Segundo Sergio Buarque de Holanda, as primeiras cabeças de gado que aqui chegaram remontam ao ano de 1549, vindas com a frota do primeiro governador-geral, Tomé de Sousa. No ano seguinte, foi desembarcada uma nova leva de animais, valorizados, nas palavras do governador-geral, como "a maior nobreza e fartura nestas partes". As criações multiplicaram-se rapidamente e, em 1552, as terras de Garcia d'Ávila, funcionário da Coroa, já se configuravam estreitas, levando-o a requerer mais terras (Holanda, 1960: 117).

No entanto, apesar do movimento de expansão de terras das sesmarias e dos desdobramentos específicos dessa história, "que fariam a Casa da Torre de Garcia d'Ávila ilustre por mais de três séculos” (Holanda, 1960: 118), a pecuária era atividade "secundária e acessória", situada num segundo plano em face de outras atividades econômicas da colônia, voltadas para exportação. 
No Nordeste, num primeiro momento, a atividade principal - a produção do açúcar para exportação - restringia a colonização à orla dos canaviais. Ao incorporar o "ziguezague sertanejo do gado" (Alencastro, 2000: 340), a colonização deslocou-se também para a zona das caatingas. Dessa forma, a criação de gado proporcionou uma "segunda dimensão da terra brasileira" (Holanda, 1960: 218). A expansão da pecuária não trouxe mudanças somente espaciais aos domínios colonizados. Ao mesmo tempo em que alargava o território, transformava a sociedade luso-brasílica, especialmente aquela que circundava a grande unidade produtora na qual estava assentada toda a estrutura econômica e social do país, baseada na grande propriedade, na monocultura e no trabalho escravo (Prado Junior, 1994: 123).

Ainda que interdependentes, as atividades desenvolvidas no interior do território e na zona litorânea forjaram relações sociais distintas. Apêndice indispensável da economia açucareira, a atividade pastoril deu origem a relações de produção que se apartavam do escravismo, engendrando uma "camada social distinta daquela do litoral" (Alencastro, 2000: 341). Alencastro salienta também que a produção de carne dos sertões influenciou o litoral, aumentando a oferta alimentar nas fazendas e engenhos e facilitando a concentração do trabalho escravo na agricultura de exportação. Sua importância também era sentida no fornecimento de animais para o trabalho nos engenhos, em boa parte acionados por tração animal, assim como para o transporte da cana das áreas de plantações para os engenhos e do açúcar para os portos de embarque, entre outras necessidades de deslocamento de cargas da época.

Concomitantemente, devido à ampliação da atividade açucareira, na medida em que aumentava a procura por bois e cavalos para o trabalho, diminuía os criatórios na zona mais próxima ao litoral, empurrando-os para o sertão, em virtude do privilégio dado ao uso das terras para economia de exportação. Pelo antagonismo que cedo se instituiu no Brasil entre a grande lavoura monocultora e a pecuária, uma foi se afastando da outra tanto quanto possível (Freyre, 1973: 36), mas, como organizações antagônicas que são, opondo-se e complementando-se a um só tempo (Andrade, 1998: 174).

Abastecendo e dando vazão aos excedentes demográficos "da mais antiga, rica e densamente povoada [área] da colônia", a zona canavieira, o hinterland atraiu indivíduos sem posses e marginais que lá encontraram um meio de vida (Holanda, 1960: 219). Para Manuel Correia de Andrade, nos primeiros tempos, os adeptos da pecuária, atividade econômica subsidiária da cana-de-açúcar, não dispunham de capital para montar engenhos, adquirir escravos e plantar canaviais, e poderiam vivenciá-la "com espírito demasiado independente para se submeterem à hierarquia social rígida da civilização açucareira" (Andrade, 1998: 137). 


\section{Oswaldo Gonçalves Júnior}

Quando Gilberto Freyre afirma não haver nem casas-grandes, nem senzalas nos sertões, em virtude da falta d'água e da ausência de solos férteis que justificassem uma agricultura hierárquica, com o "senhor a cavalo mandando o negro fazer isso, fazer aquilo, e o escravo a pé fazendo tudo, junto com a besta e com o boi" (Freyre, 2004: 108), deve ter sido influenciado pelas características mais livres do manejo do gado, já que estudos posteriores "constataram também aí a presença de escravos de origem africana, ao lado da gente livre pobre" (Fausto, 1995: 84). O mesmo Freyre, numa passagem de Casa-grande E senzala, fornece mais um dado que possibilita compreender melhor sua percepção, talvez mais voltada para o menor peso daquelas relações de poder do que para a demografia escrava, já que para cá foram também trazidos "negros entendidos na criação de gado e na indústria pastoril” (Freyre, 1973: 309).

De forma geral, a maior liberdade ou mobilidade social parecem ter exercido considerável atração para a sociedade que se forjou em torno dos engenhos do litoral. Todavia, mesmo sob o efeito desse aspecto positivo, o lento processo de ocupação dos sertões pelos colonizadores não foi sem percalços. Não foi por acaso que Gustavo Barroso chamou esse processo de ocupação de terras pouco valorizadas, sem metais preciosos, áridas e habitadas por indígenas resistentes à invasão de "uma das grandes epopeias da formação do Brasil" (Barroso, 2004: 13). Também não por acaso que a figura central nesse processo é a do sertanejo que, na definição de Euclides da Cunha "é, antes de tudo, um forte" (Cunha, 1968: 86).

Para Caio Prado Junior, esse "caráter épico" da pecuária dos sertões, "tão bem pintados por Euclides da Cunha [seria] admirável nos seus efeitos dramáticos, mas deplorável no terreno prosaico da economia" (Prado Júnior, 1994: 199). Examinaremos mais de perto essa questão nos próximos tópicos.

\section{Pecuária bovina e status social}

Segundo Sergio Buarque de Holanda, desde os fins do século XVII, apesar de a população ser rala, o Sertão do Nordeste encontrava-se devassado e ocupado. A ocupação de seu território não foi uniforme, concentrando-se ao longo dos rios, sendo praticamente inexistente em outras áreas, aquelas apenas atravessadas pelas rotas de boiadas. As vilas da região surgiram principalmente no século XVIII, sendo geralmente insignificantes e de crescimento lento (Holanda, 1960: 221-222).

No processo de conformação desse espaço, mediante sua ocupação e organização, uma delimitação legal incidiu mais diretamente sobre a prática da pecuária. Trata-se da Carta Régia de 1701, cuja preocupação maior era evitar 
que a pecuária atrapalhasse a atividade canavieira. Para tal, determinou que a criação de gado fosse proibida de ser praticada numa faixa de dez léguas (aproximadamente 80 quilômetros), contadas a partir da franja litorânea (Fausto, 1995: 84).

O avanço do movimento (re)povoador no distante Sertão foi fundamentalmente concretizado por indivíduos não proprietários, que, em outras palavras, não dispunham de prestígio para influenciar o poder para conseguirem doações de terras ou sesmarias. Dispostos a "enfrentarem o calor e a sede das caatingas adustas" (Andrade, 1998: 168), esses homens - que, num primeiro momento, supriam, quase sempre, a ausência dos proprietários legais, na condição de vaqueiros e administradores, e, com o passar dos séculos, na condição de posseiros, foreiros ou rendeiros - ainda não teriam tido seu justo reconhecimento pelos narradores, como reclama Manuel Correia de Andrade, assim como o tiveram os latifundiários da Casa da Torre. Esses herdeiros de Garcia d'Ávila, pela sua influência e poder, chegaram a possuir 340 léguas de terras, extensão maior que muitos reinos europeus de então (Andrade, 1998: 168).

Em Formação do Brasil contemporâneo (1942), Caio Prado Junior vê coerência nesse sistema de organização do espaço agrário, no qual a concessão de sesmarias visava atender às expectativas dos colonos de origem fidalga ou nobre que, não pretendendo levar aqui "vida mesquinha de pequeno camponês", não poderiam aceitar outra coisa senão grandes extensões de terra (Prado Junior, 1994: 120). Como sistema de produção, a monocultura acompanharia necessariamente a grande propriedade tropical. Correlatas, teriam por objetivo único a produção de certos gêneros de grande valor comercial e, por isso, altamente lucrativos. Se assim não fosse, não seria tentada ou logo pereceria. Seria natural, portanto, que todos os esforços fossem canalizados para aquela produção. Para o autor, no processo de (re)ocupação do Sertão, o que "prevalece é o grande proprietário absentista, senhor às vezes de dezenas de fazendas, que vive nos centros do litoral e cujo contacto único com as propriedades consiste em receber-lhe os rendimentos" (Prado Junior, 1994: 191).

$\mathrm{O}$ isolamento dos habitantes dos sertões nordestinos contribuiu para forjar um estilo de vida que possibilita compreender melhor o termo "civilização do couro". Pela importância central na sociedade que lá se estabeleceu, a atividade pecuária, apesar de todas as dificuldades, definiu ao longo do tempo um modus vivendi que carrega consigo um significativo arcabouço cultural. Para tal, conforme Capistrano de Abreu observa, muito contribuiu a inclinação dos sertanejos pelo trabalho nas fazendas de gado, em que se empenhavam ativamente, "consistindo toda a sua maior felicidade merecerem algum dia o nome de vaqueiro. Vaqueiro, criador ou homem de fazenda são títulos honoríficos entre eles" (Abreu, 1907: 329). 


\section{Oswaldo Gonçalves Júnior}

Contrastando com a rigidez social da área canavieira, a possibilidade de mobilidade social era muito maior no contexto pecuário sertanejo. $O$ vaqueiro começava a ser pago depois de quatro ou cinco anos de serviço e o sistema de pagamento utilizado baseava-se nas crias nascidas - em quatro crias, uma caberia ao vaqueiro. Após algum tempo, o vaqueiro podia então constituir seu rebanho, tendo chances de fundar sua própria fazenda. $\operatorname{Em} A$ terra e o homem do Nordeste, publicado originalmente em 1963, Manuel Correia de Andrade afirma que essa prática teria "uso ainda generalizado no Sertão" (Andrade, 1998: 159). Já no Agreste, segundo o autor, o pagamento com base nas crias nascidas, à medida que a pecuária se tornava mais intensiva, foi sendo substituído pelo salário, "proletarizando" os vaqueiros e "minguando" suas possibilidades de um dia também virem a se tornar fazendeiros.

Estrutura-se, pois, por detrás das oportunidades oferecidas pelos sertões, um sistema de relações sociais no qual o vaqueiro era muito mais que um simples encarregado, um "tomador de conta de reses" (Chandler, 1980: 164). A começar pela sua importância na hierarquia da sociedade pecuária. Depois do patrão, a pessoa mais importante na fazenda era, em geral, o vaqueiro. Nas fazendas pequenas, quando não havia vaqueiro o patrão fazia suas vezes, situação que se tornava mais comum na medida e nas localidades em que se expandia o processo de divisão de terras. Nas fazendas onde os donos não residiam, quem realmente dirigia tudo era o vaqueiro. Por essas características, o vaqueiro gozava de muito prestígio social, conclui Chandler.

Para Caio Prado Junior, essa forma de remuneração contribui para a multiplicação das fazendas, já que o vaqueiro, recebendo seu pagamento em cabeças de gado, podia estabelecer-se por conta própria, fundando novas unidades, adquirindo terras ou, mais comumente, arrendando-as dos grandes sesmeiros. Ainda que o autor deixe claro que esse tipo de propriedade nem de longe era predominante como o fora o do grande proprietário absentista, as fazendas nas mãos dos vaqueiros eram mais modestas, e eles participavam direta e inteiramente do trabalho que ali era feito.

Esses aspectos ligam-se ainda a mais dois, que imprimem uma "facilidade incrível", nas palavras de Prado Junior, para que se estabeleça uma fazenda, estendendo as possibilidades daqueles possuidores de recursos escassos: o crescimento do consumo do litoral e da região das minas (Minas Gerais), que estimulou a ampliação da produção pecuária; e o fato de para se formar uma fazenda ser necessário, apenas, levantar uma casa e currais rudimentares. Além disso, o pessoal necessário resumia-se a alguns homens. Por conseguinte, não faltaria mão de obra porque, não havendo escravos, bastariam "mestiços de índios, mulatos ou pretos que abundam nos sertões, e que, ociosos em regra e avessos em princípio ao trabalho, têm uma inclinação especial para a vida aventuresca e de 
esforço intermitente que exigem as atividades da fazenda" (Prado Junior, 1994: 191).

Não obstante essas considerações, importa salientar que o aspecto remuneratório, além de ter contribuído para a expansão das fazendas - com os vaqueiros tornando-se donos de fazenda por "vaqueirice" (Jucá, 1995: 35) -, representava, para os quase sempre distantes proprietários, “(...) um ótimo método para fazer com que o vaqueiro se interessasse pelo desenvolvimento da criação" (Holanda, 1960: 223).

Foi nessa estrutura agrária que o sertanejo, na figura do vaqueiro, se tornou típico e central na sociedade dos sertões. Indivíduo "merecedor de respeito, em razão da superioridade que lhe conferia o conhecimento da terra, do gado, dos métodos de criação e a responsabilidade direta das cousas da fazenda" (Jucá, 1995: 35), não foi por acaso que alcançou tamanho destaque, fazendo-se presente ainda hoje, em suas muitas ressignificações, no imaginário social nacional, extrapolando o espaço dos sertões.

\section{Apogeu e queda da pecuária sertaneja}

Paralelamente à construção e à posterior estabilização das estruturas agrárias típicas do Sertão, estabelecia-se um modo de vida em torno da unidade econômica e social representada pela fazenda. A partir do século XVIII, intensificou-se o movimento de fixação de donos de fazendas e suas famílias no interior, com o surgimento de casas sólidas e espaçosas, embora, de um modo geral, sem a opulência das casas-grandes da zona canavieira (Centro Dragão do Mar de Arte e Cultura, 1999).

Ainda que, em algumas regiões a utilização da terra para fins comerciais tenha demorado mais que em outras, o gado acabou por revelar-se, em virtude da já mencionada ampliação do consumo no litoral e na zona de mineração, uma mercadoria de condições excepcionais, já que representava valor em si mesmo e transportava a si mesmo (Jucá, 1995: 37). Assim, a capacidade de auto-transportar-se e de percorrer enormes distâncias, que tornava possível o abastecimento de mercados consumidores distantes, acabou fazendo da pecuária uma atividade economicamente atraente para os sertões.

Foi ainda no século XVIII que uma alteração fundamental revolucionou a produção nordestina. Como a Bahia e Pernambuco eram os maiores centros consumidores do Nordeste, o gado vindo de locais distantes como o Ceará tinha seu custo aumentado em relação ao gado proveniente dos sertões norte-rio-grandense e paraibano. Esse aspecto, somado aos tributos cobrados nos deslocamentos e para participação nas feiras em que o gado era vendido, 


\section{Oswaldo Gonçalves Júnior}

diminuía os lucros com as boiadas e determinou a exportação via marítima das reses já abatidas, transformadas em carne seca, salgada e em couros (Girão, 1995: 65).

Com a intensificação desse processo e de seus desdobramentos, o charque veio a se tornar "um dos produtos mais importantes no comércio interno da colônia" (Holanda, 1960: 224). Segundo Valdelice Carneiro Girão, a comercialização de carne e de couro tomou tamanha dimensão que, em 1757, comerciantes pernambucanos propuseram ao governo português, ainda que sem sucesso, a criação de uma Companhia de Carne Seca e Couros do Sertão, com vistas a exportar os produtos para outras regiões da colônia (Girão, 1995: 66).

No entanto, essa situação virtuosa perdurou somente até o final do século XVIII. Em meados do século, a pecuária de Minas Gerais, que se dava em condições naturais mais favoráveis e se utilizava de técnicas mais aprimoradas, já retirava o abastecimento da zona mineradora da pecuária nordestina (Prado Junior, 1994). Além disso, a recorrência das secas, que se sucediam com regularidade dramática, comprometia enormemente o desenvolvimento da criação de gado no Nordeste.

A literatura que faz referência a essas secas traz sempre dados impressionantes sobre a quantidade de animais perdidos, acompanhados do êxodo maciço da população e da morte de pessoas. Com efeitos profundos e duradouros nos anos que as sucediam, as secas ocasionavam o desaparecimento de rebanhos inteiros e fortunas pessoais. Até mesmo indivíduos antes considerados ricos começavam a "sentir o gosto amargo das privações", como ressalta Chandler (1980: 200). De forma avassaladora, a seca provocava um "estado geral de desânimo, causando uma desmoralização geral" (Chandler, 1980: 202), e esse estado não era completamente revertido ao longo do tempo exatamente pela recorrência do fenômeno. Segundo Gomes (2001: 8), nas épocas de seca, o Sertão mostrava sua face mais cruel, "a da terra onde os ricos são pobres e os pobres, miseráveis".

Para a pecuária, a principal atividade econômica dos sertões, o golpe fatal parece ter vindo com a seca que durou de 1790 a 1793 . Conhecida como "Seca Grande", essa longa estiagem foi responsável pela transferência do centro produtor de charque do Nordeste para o Rio Grande do Sul. Todavia, da mesma forma que já existia anteriormente a esse período áureo, a pecuária continuou marcando presença nos sertões. Nas palavras de Gustavo Barroso, isso aconteceu porque, após as secas, "sobrou sempre e sempre há de sobrar semente de gado e semente de gente para continuar a luta travada ali entre o homem e a natureza" (Barroso, 2004: 15). Discorrendo sobre esse processo de decadência, Caio Prado Junior afirma que o sertão jamais se recuperaria deste golpe: "Vegetará daí por diante num estado crônico de debilidade congênita que se prolongará até nossos dias" (Prado Junior, 1994: 196). 


\section{O papel social dos bichos}

No espaço em foco, além do gado bovino, diferentes espécies animais exerceram importância material e simbólica. Essas funções, quando desnudadas, contribuem para uma melhor compreensão da sociedade sertaneja.

Em Nordeste - aspectos da influência da cana sobre a vida e a paisagem do Nordeste do Brasil (1937), Gilberto Freyre dedica um capítulo inteiro ao tema. Ainda que seu foco recaia sobre a zona canavieira, traz elementos importantes para compreensão das relações entre seres humanos e animais, estabelecidas na região em seu conjunto. Para o autor, o cavalo e o boi foram os dois grandes animais da civilização do açúcar. Quanto ao primeiro, Freyre fala que o senhor de engenho foi quase um "centauro, metade homem, metade cavalo" (Freyre, 2004: 98-99). O aristocrata conseguia se posicionar sobre o animal praticamente na mesma altura que a casa-grande lhe proporcionava, possibilitando assim o "exercício em movimento de domínio sobre as massas". Tratado com cuidado e bem alimentado, o cavalo do senhor de engenho diferenciava-se dos cavalos dos sertanejos, mais "angulosos e ossudos". Resistindo às duras condições dos sertões e tendo que penetrar no emaranhado das caatingas, tanto o cavalo quanto o cachorro do sertanejo eram auxiliares imprescindíveis para a execução do seu trabalho de vigilância e caça. Da mesma forma que o gado, ambos não possuíam raça definida, resultando das adaptações ao ambiente e dos cruzamentos sofridos ao longo de gerações.

Quanto ao gado bovino, Freyre afirma que o fenômeno em torno de seu prestígio não era originário daqui. Em Casa Grande E Senzala (1933), o autor, analisando os estudos de Melville J. Herskovits sobre a África, afirma que na porção oriental daquele continente, de predomínio banto, a posse de gado numeroso, e não a de grandes extensões de terras, é que conferia prestígio social aos indivíduos (Freyre, 1973: 309). Nos sertões, para além da faceta de prestígio própria aos vaqueiros e ao gado bovino, gentes pobres orbitavam a atividade da pecuária, dedicando-se a trabalhos eventuais ligados a ela e, sobretudo, à agricultura, atividade colonizadora que data da mesma época do desbravamento do interior pela pecuária. Ela era feita "mediocremente e de forma penosa", ocupando pequenos roçados sem importância comercial e visando o abastecimento dos moradores da fazenda, que necessitavam "equilibrar uma difícil situação entre o isolamento e a autossuficiência" (Andrade, 1998: 174). Muitas vezes essa agricultura era insuficiente até mesmo para cumprir devidamente seu caráter de subsistência (Jucá, 1995: 36).

Isso, no entanto, parece não ter sido exclusivo dos sertões. No litoral, o interesse centrado na monocultura canavieira provocou fenômeno semelhante, 


\section{Oswaldo Gonçalves Júnior}

como observa Gilberto Freyre, ao afirmar que "por mais esquisito que pareça, faltava à mesa de nossa aristocracia colonial legumes frescos, carne verde e leite" (Freyre, 1973: 36-37). No século XVIII, a "falta de farinhas" chegou a tal ponto que, na Bahia, o governo mandou "incluir nas datas de terra a cláusula de que ficava o proprietário obrigado a plantar 'mil covas de mandioca por cada escravo que possuísse empregado na cultura da terra"” (Freyre, 1973: 37).

A diversificação das atividades econômicas nos domínios das fazendas era representada pela lavoura de subsistência ${ }^{1}$ e também pela criação de jumentos, porcos, cabras e ovelhas, que desempenhavam funções de trabalho e serviam à alimentação de forma complementar, da mesma forma, em relação a esse último item, que galinhas e patos. Diante dessa diversidade, uma análise da dimensão alimentar como elemento cultural que define hábitos e costumes seria certamente reveladora, mas foge por hora das possibilidades analíticas deste artigo. Ainda assim, cabe apontar que não negamos a importância daquilo que alguns autores vêm denominando de "ideologias alimentares", fenômeno cognitivo e simbólico que faz parte do conhecimento social da população e que comporta uma série de representações definidoras de qualidades estimuladoras ou inibidoras do consumo de determinados alimentos (Canesqui, 1988: 211). Entre outros aspectos, as relações entre o alimento e o organismo que o consome refletiriam, simbolicamente, a posição social do indivíduo (Woortmann, 1978: 4).

No espaço dos sertões, caprinos e ovinos foram animais em geral desprestigiados, juntamente com outros animais de pequeno porte, genericamente chamados de "miunças", expressão não só de seu menor porte, mas também de sua menor importância econômica. Em seu aspecto positivo, as cabras aparecem como "cabras de leite", animal destinado ao sustento de crianças de colo, em geral de pobres e sertanejos. Dependendo da agudez da seca e da pobreza, podia se considerar rico quem as tivesse (Andrade, 1998: 150). Outra utilidade relacionava-se ao fornecimento de peles, matéria-prima largamente utilizada na confecção da indumentária dos vaqueiros. No âmbito do grande comércio, a pele chegou a ser produto de exportação de relativa importância e que, no início do século XX, fizera do Brasil o segundo maior fornecedor do produto em escala mundial. Mas, de forma geral, na realidade dos sertões, a comercialização desses animais "era quase inexistente, embora sua pele valesse alguns réis" (Chandler, 1980: 173).

Todavia, seu aspecto negativo é que mais se destaca nos relatos. Nos domínios da grande lavoura, cabras e ovelhas chegavam a ser consideradas como "criaturas inúteis", como lembra Freyre (1973: 76). Mais que isso, os caprinos eram vistos como inimigos da cana e deveriam ser evitados como forma de se prevenir contra danos às plantações, já que "bastava que começasse o brotamen- 
to no campo trabalhado que lá iam elas investirem contra as plantas", alimentando-se. Baseado em Corografia Brasílica (1817), de Manuel Aires de Casal, primeiro livro publicado no Brasil, Gilberto Freyre afirma que muitos animais eram mortos face ao descumprimento da advertência de serem mantidos presos em cercados (Freyre, 1973).

No entanto, ao que parece, os caprinos não manifestavam, em seus hábitos alimentares, nenhum interesse especial pela cana, como lembra Freyre. Referindo-se aos estudos de Alberto Löfgren (1864-1918) sobre o problema florestal do Nordeste, Freyre afirma que o botânico sueco radicado no país não teria hesitado em "incluir bicho tão daninho, quando criado à solta, entre as 'causas artificiais' que vêm contribuindo para o aumento da desnudação nos trechos já saarizados do Nordeste" (Freyre, 2004: 111). Argumento como esse fora ouvido de forma recorrente por ocasião das pesquisas de campo que originaram este estudo, mantendo-se, portanto, na atualidade, um diagnóstico semelhante sobre o problema. Não obstante, "criada de outro jeito, isto é, sob vigilância ou dentro de cercado, a cabra poderia ser um animal realmente útil" (Freyre, 2004: 111).

Segundo Castro (1984: 45), na Espanha, a percepção negativa sobre estes animais teria levado à legislação de 1819 , que "permitia matar cabras como se fossem animais de caça", e outra, de 1826, que determinava a "matança geral de cabras", ambas medidas voltadas para evitar a destruição da vegetação. Essas drásticas medidas revelaram-se inócuas, uma vez que, nos dias de hoje, a produção espanhola de leite e queijo de cabra é bastante significativa. Castro fornece ainda outro exemplo de estigmatização. Nos Estados Unidos, quem "se dedicava à criação de cabras era ridicularizado", numa perspectiva "manifestamente desfavorável à importância da cabra leiteira", tida como animal de mau cheiro, depredador, insignificante e desprezível. Um exemplo contrário viria da França, país no qual a cabra era considerada como a "vaca democrática", num "sentido positivo, construtivo, e de realidade econômica". Naquele país, depois que os caprinocultores se organizaram em nível nacional, o que era antes uma atividade complementar a um magro rendimento da agricultura familiar, passou a ter sentido econômico e a ser fonte de riqueza (Castro, 1984: 81).

Se os caprinos destacam-se por suas características comportamentais que envolvem habilidade e esperteza e que dificultam seu confinamento, o que acabou por reforçar seu caráter negativo para a agricultura de exportação do Nordeste, para Gilberto Freyre os ovinos teriam sua rejeição advinda do fato de carregarem um caráter místico ou religioso - como animal simbólico do Redentor, "cordeiro de Deus que tira os pecados do mundo". Esse traço cultural explicaria o baixo consumo de sua carne pela população, tanto no Nordeste quanto no restante do Brasil, nas primeiras décadas de século XX (Freyre, 2004: 115). 


\section{Oswaldo Gonçalves Júnior}

Subutilizados historicamente por restrições que os impediram de progredir nas zonas mais prósperas da economia agrária de exportação, empurrando-os para o ambiente da população mais pobre dos sertões, no qual permaneceram relegados a um segundo plano, os ovinos eram representados de forma quase exótica, e este era seu lado mais visível, especialmente por aqueles que não dependiam diretamente desses animais para sua sobrevivência,. No entanto, para além das representações envoltas em muitos folclores e histórias, ovelhas e principalmente cabras - e mesmo sendo raras as referências a elas nos textos dos_autores consultados que se dedicaram ao tema tratado neste artigo - disseminaram-se pelos sertões de forma impressionante e silenciosa, quase tão silenciosa quanto a população pobre que recheou de vida a porção sem prestígio desse mundo sertanejo.

\section{Permanências no tempo e outras conclusões}

Diversos testemunhos sobre o processo de deslocamento em direção aos sertões nordestinos a partir do século XVI - desde anônimos até o jesuíta Antonil, talvez o mais considerado de todos, e que publicou, em 1711, Cultura e opulência do Brasil por suas drogas e minas - embasam boa parte dos trabalhos de historiadores e outros cientistas sociais que estudaram o tema. Neles é destacada sua importância no processo de constituição da nação e ressaltada suas peculiaridades enquanto fenômeno social.É o caso dos autores clássicos citados neste artigo, que abriram caminho para outros que vieram a seguir. Sua leitura traz elementos reveladores sobre aspectos da vida sertaneja e do valor social da pecuária bovina, cujos reflexos atravessam o tempo.

Sob uma perspectiva histórica, o estudo dessas fontes faz-nos crer que a pecuária bovina constituiu um importante mecanismo de ascensão social para aqueles que, embora homens livres numa sociedade escravocrata, eram despossuídos de bens. Tornar-se vaqueiro e após um tempo receber como forma de pagamento algumas reses podia significar começar sua própria fazenda e criação, algo extraordinário para uma sociedade altamente restritiva em oportunidades como a colonial. Não por acaso, também por isso o vaqueiro foi o grande personagem dos sertões, "aquilo que todos queriam ser". No campo das mentalidades, o vaqueiro, figura emblemática do Sertão - papel que desempenha ao longo dos séculos, mesmo com o tempo e a modernidade que pressionam pelo seu desaparecimento - mantém presente sua mística no imaginário social (Centro Dragão do Mar de Arte e Cultura, 1999).

Além de povoar o imaginário social, sobretudo no mundo rural, a pecuária bovina, enquanto prática econômica, determinou a criação de mercados cla- 
ramente identificados, ligados a zonas economicamente mais prósperas, ainda que a decadência viesse solapando a atividade após seu auge, atingido com as “charqueadas" (Girão, 1995), no século XVIII. Em seu apogeu, a pecuária bovina proporcionou aos sertões, ainda que num período relativamente curto, um patamar econômico nunca visto. Por mais que hoje enfrentem limitações evidentes, os produtos do gado bovino ainda contam com um mercado estabelecido, estimulando uma aposta nessa atividade, que dosa aspectos do imaginário social e da "economia de fato".

Ainda que não se possa afirmar categoricamente, dada a temporalidade implicada, a existência de uma relação rígida entre essas constatações e a problematização aqui levantada, também não se pode negar que as mentalidades envolvidas deixem de ser influenciadas por esse peso da história, sobretudo em áreas dos sertões onde a manutenção de formas de sociabilidade seguiu um ritmo próprio, mantendo-se "inalteradas" por mais tempo, como enfatizam alguns dos autores citados.

Numa perspectiva histórica, essa característica temporal fundamental distinguiu áreas do Sertão de outras regiões, já que nelas a pecuária se estendeu sem sofrer alterações significativas em suas "estruturas seculares" (Andrade, 1998: 186). Billy Jaynes Chandler, ao realizar suas pesquisas de campo na região dos Inhamuns, no Sertão cearense, na segunda metade dos anos 1960, afirma que as coisas "aparentemente, não mudaram muito desde o século XVIII" (Chandler, 1980: 162), não tendo constatado, no período de 225 anos coberto por sua pesquisa, mudanças significativas nem na agricultura nem na pecuária. Como já afirmado, se essas constatações ajudam a realçar o foco assumido neste artigo, não obstante não devem eliminar outras possibilidades existentes na vastidão dos sertões no âmbito das relações sociais que lá se estabeleceram. Essa observação torna-se importante para dosar, com a devida cautela, o cunho dessas generalizações, que cumprem aqui o papel de enfatizar um aspecto da realidade estudada.

No contexto atual - em que a decadência da pecuária bovina, elemento representativo da economia tradicional do semi-árido (Gomes, 2001) prevalece em boa parte dos sertões -, a caprinovinocultura vem sendo cada vez mais reconhecida como a prática mais adaptada às condições do semi-árido, fato amplamente exposto por diversos estudiosos do tema. Diante dessa constatação, se a opção pela pecuária bovina seguiu historicamente uma lógica em que fatores de ordem econômica foram decisivos para estimular a insistência na atividade ao longo dos séculos, caberia questionar a racionalidade nessa aposta diante das enormes perdas causadas pelas secas que, recorrentemente, assolam a região e dizimam as criações. Entende-se, na perspectiva deste artigo, que, além dos aspectos ligados às mentalidades e valores em torno do prestígio e status social, a existência de 


\section{Oswaldo Gonçalves Júnior}

mercados consumidores em zonas prósperas e distantes tenha constituído um dos fatores centrais, aquilo que fazia crer valer a pena o risco das perdas pelas constantes intempéries climáticas, mantendo acesa a chama da esperança de que, quem sabe um dia, era possível "fazer fortuna" por meio da criação e do comércio de gado bovino.

No entanto, se olharmos para a "cronologia das secas" no Nordeste, conforme a apresentada por Gustavo Maio Gomes em Velhas secas em novos sertões (2001), é possível ver, por exemplo, que ocorreram, tanto no século XIX quanto no século XX, 24 anos somados de períodos de seca. Em outras palavras, praticamente $1 / 4$ de cada um desses séculos foi vivido sob um cenário de devastação de rebanhos e de seres humanos. A título de ilustração, de acordo com aquele autor, na chamada Grande Seca de 1877-1879, teriam morrido 500 mil pessoas somente na então província do Ceará. Tal cenário, portanto, coloca em questão a "racionalidade econômica" envolvida nessa escolha, abrindo espaço para as mentalidades e valores ligados a prestígio e a status social como ordenadores dessa lógica. Passados séculos, com as regiões enfocadas mergulhando num quadro de decadência no que se refere à sua economia agropecuária tradicional, isso fica ainda mais evidente e se torna muito difícil de não se questionar no que se refere à sua manutenção.

Chandler, por exemplo, ao estudar a história da poderosa família Feitosa e sua influência no sertão dos Inhamuns por mais de 200 anos, do século XVIII até o final da República Velha, ajuda a reforçar essa perspectiva, ressaltando que seu declínio relativo teria sido acelerado pela "importância que davam às prestigiosas atividades pecuárias, mesmo quando outros haviam conseguido construir uma base econômica mais sólida através da agricultura", e pela "destruição periódica de seus únicos recursos produtivos - os rebanhos de gado - pelas secas" (Chandler, 1980: 204).

Logicamente, essa visão privilegiada que o presente proporciona sobre o passado obriga a relativizar a ação daqueles que insistiram nessa opção, escravizados por uma visão de mundo que possivelmente não permitia enxergar para além daquilo que estava posto. E mesmo que o fizessem, as opções disponíveis muito provavelmente os conduziriam novamente para os mercados estabelecidos da prática consolidada da pecuária bovina, com suas expectativas de ganhos, ainda que com os riscos a correr. Esse certamente não é o quadro que se apresenta hoje, ainda que também não se pretenda culpabilizar aqueles que ainda se mantêm presos àquela tradição, e que ainda sofrem todos os prejuízos por isso.

Como constatado em pesquisas realizadas, uma série de ações vem sendo desenvolvida visando ao aprimoramento das práticas e à construção de mercados para caprinovinocultura. Essas iniciativas abrem novas brechas que permi- 
tem que cada vez mais adeptos vislumbrem novas perspectivas de futuro na agropecuária, desta vez com a caprinovinocultura e de acordo com um paradigma no qual a perspectiva de combate às secas vem sendo substituído pela visão de convivência com elas (Silva, 2007).

Embora represente importante alternativa de sobrevivência para milhões de pessoas ao redor do mundo, a criação de caprinos e ovinos vem sendo estigmatizada há muito tempo (Pomponet, 2009). Atrelada historicamente à população mais pobre do Nordeste brasileiro, a caprinovinocultura começou a experimentar mudanças significativas na última década, sobretudo através dos esforços conjuntos de agentes-chaves e de políticas públicas, que apostam nas suas potencialidades (Gonçalves, 2010a; 2010b) e que procuram promover o aproveitamento das possibilidades que se apresentam para reversão de um quadro marcado pela exclusão social e por uma vocação regional desperdiçada. Além dos elementos que fornece sobre o passado, a perspectiva histórica propicia uma melhor compreensão do estágio em que se encontra esse fenômeno, fértil em seus aspectos de construção social, e das modificações decorrentes nesse espaço.

Nota

1. Uma exceção nesse quadro foi a cultura do algodão, que, na virada do século XVIII para o XIX, revolucionou o campo nordestino,

Referências bibliográficas

ABREU, Capistrano de. Capítulos de História Colonial (1500 - 1800) - Biblioteca Nacional - Grandes Nomes do Pensamento Brasileiro-Folha de SP / Publifolha [1907]. Disponível em: http://www.biblio.com.br/ gerando riquezas que atraíram segmentos sociais mais abastados para a atividade (Andrade, 1998). 
Sul. São Paulo: Companhia das Letras, 2000.

ANDRADE, Manuel Correa de. A terra e o homem do Nordeste. $6^{\mathrm{a}}$ ed. Recife: Editora UFPE, 1998.

ANTONIL, André J. Cultura e Opulência do Brasil por suas Drogas e Minas. $3^{\mathrm{a}}$ ed. Belo Horizonte: Itatiaia/Edusp, 1982. (Coleção Reconquista do Brasil). Disponível em: $<$ http://www.dominiopublico.gov.br/dow nload/texto/bv000026.pdf. $>$. Acesso em: 14 out. 2008.

BARROSO, Gustavo. Terra de Sol-natureza e costumes do Norte. Fortaleza: Edições Demócrito Rocha, 2003.

À margem da história do Ceará. Rio de Janeiro - São Paulo - Fortaleza: FUNCET, 2004.

CANESQUI, Ana Maria. Antropologia e alimentação. Revista de Saúde Pública, São Paulo v. 22, n. 3, 1988, p. 207-216.

CASTRO, Aristóbulo de. A cabra. $3^{\text {a }}$ ed. Rio de Janeiro: Freitas Bastos, 1984.

CENTRO DRAGÃO DO MAR DE ARTE E CULTURA (CDMAC). Folder da Exposição permanente "Vaqueiros". Fortaleza, 1999.

CHANDLER, Jaynes B. Os Feitosas e o sertão dos Inhamuns: a história de uma família e uma comunidade no Nordeste do Brasil (1700 - 1930). Fortaleza: Edições UFC; Rio de Janeiro: Civilização Brasileira, 1980.

CUNHA, Euclídes da. Os sertões. $27^{\mathrm{a}}$ ed. Rio de Janeiro: Livraria Francisco Alves, 1968.

FAUSTO, Boris. História do Brasil. São Paulo: Edusp, 1995.

FREYRE, Gilberto. Casa-grande E Senzala. $16^{\mathrm{a}}$ ed. Rio de Janeiro: José Olympio Editora, 1973.

. Nordeste: aspectos da influência $d a$ cana sobre a vida e a paisagem do Nordeste do Brasil. $7^{\mathrm{a}}$ ed. São Paulo: Global, 2004.
GIRÃO, Valdenice C. As charqueadas. In SOUZA, Simone. História do Ceará. Fortaleza: Fundação Demócrito Rocha, 1995.

GOMES, Gustavo M. Velhas secas em novos sertões: continuidade e mudanças na economia do Semi-árido e dos Cerrados nordestinos. Brasília: IPEA, 2001.

GONÇALVES, Oswaldo Jr. Da tradição ao mercado: construção social e caprinovinocultura no Semi-árido. 2010. Tese (Doutorado em Administração Pública e Governo)-Escola de Administração de Empresas de São Paulo da Fundação Getulio Vargas. São Paulo, 2010.

HOLANDA, Sérgio B. de. História Geral da Civilização Brasileira. Tomo I - A época colonial. Volume 2 - Administração, economia, sociedade. São Paulo: Difusão Européia do Livro, 1960.

História Geral da Civilização Brasileira. Tomo I - A época colonial. Volume 1 Do descobrimento à expansão colonial. $5^{\mathrm{a}} \mathrm{ed}$. São Paulo/Rio de Janeiro: Difel, 1976.

JUCÁ, Gisafran N. À guisa de introdução o espaço nordestino. O papel da pecuária e do algodão. In SOUZA, Simone (org.), História do Ceará. Fortaleza: Fundação Demócrito Rocha, 1995.

NOBRE, Fernando V. A caprinovinocultura no Rio Grande do Norte. Aspectos mercadológicos na Grande Natal, 2007 (mimeo).

POMPONET, Andre. Do autoconsumo ao mercado: os desafios atuais para a caprinocultura no nordeste semi-árido da Bahia. In: XLVII Congresso da Sociedade Brasileira de Economia, Administração e Sociologia Rural, 2009, Porto Alegre, RS. Anais eletrônicos... Brasília: SOBER, 2009. Disponível em: <http://www.sober.org.br/ palestra/13/250.pdf $>$. Acesso em 14 out. 2009.

PRADO JUNIOR, Caio. P. Formação do Brasil Contemporâneo. 23 $3^{\mathrm{a}}$ ed. Brasiliense: São Paulo, 1994. 
SILVA, Roberto Marinho Alves da. Entre o combate à seca e a convivência com o semiárido: políticas públicas e transição paradigmática. Revista Econômica do Nordeste, Fortaleza, v. 38, n.3, jul-set, 2007 (Documentos Técnico-Científicos), p. 464-485.
WOORTMANN, Klaas. Hábitos e ideologias alimentares em grupos sociais de baixa renda: relatório final. Brasília, 1978. (Série Antropologia, 20). Disponível em: $<$ vsites.unb.br/ics/dan/Serie20empdf.pdf $>$. Acesso em: 10 abr 2009.

\title{
Resumo
}

Uma cultura de resistência no semi-árido, expressa por mentalidades e valores, incide contra o potencial econômico da caprinovinocultura, vista de maneira inferiorizada em relação à pecuária bovina, atrelada historicamente a prestígio e status social. $\mathrm{O}$ artigo procura lançar luz sobre aspectos que possibilitem tornar mais claras as raízes do aparato cognitivo que sustenta essa visão, recorrendo-se para isso à produção de autores relevantes que tratam do tema do deslocamento colonizador e da pecuária nos sertões. Em última análise, busca elementos da influência do processo histórico de organização econômica e social desse espaço sobre o presente.

Palavras-chave: pecuária; caprinovinocultura; semi-árido; prestígio; status social.

\begin{abstract}
A culture of resistance in the semi-arid, expressed by mentalities and values, goes against the economic potential of sheep and goat raising, considered as an inferior activity when compared to the cattle raising, historically linked to social status and prestige. This paper attempts to shed light on aspects that make possible to clarify the roots of the cognitive apparatus that supports this view, resorting to it to the production of relevant authors dealing with the issue of displacement of colonizer and livestock in the hinterlands. Ultimately, it seeks evidence of the influence of the historical process of economic and social organization of space on the present.

Keywords: cattle raising; sheep and goat raising; Semi-arid; prestige, social status.

\section{Résumé}

Une culture de résistance dans le semi-aride, exprimée pour mentalités et valeurs, va contre le potentiel économique de l'élevage de caprins et d'ovins, vu de façon inférieur par rapport au bétail bovin, historiquement lié au prestige et au statut social. Larticle cherche faire la lumière sur les aspects
\end{abstract}


qui permettent clarifier les racines de l'appareil cognitif qui soutient ce point de vue, en utilisant comme recours la production des auteurs pertinents qui traitent du sujet du déplacement colonisateur et d'élevage au intérieur du pays. En fin de compte, il cherche les preuves de l'influence du processus historique de l'organisation économique et sociale de cet espace sur le présent.

Mots-clés: élevage bovin; élevage caprin et ovin; semi-aride; prestige; statut social. 